\title{
Comunicação multimodal na sala de aula de ciências: construindo sentidos com palavras e gestos
}

\section{(Multimodal communication in the science classroom: making meaning with words and gesture)}

\author{
Cláudia Piccinini \\ Isabel Martins \\ Programa de Pós-graduação Tecnologia Educacional nas Ciências da Saúde \\ Núcleo de Tecnologia Educacional para a Saúde/UFRJ
}

\section{Resumo}

Questionar a centralidade atribuída à linguagem como recurso para a construção de significações nas salas de aula de Ciências é algo que se faz necessário e urgente no atual contexto de reconhecimento do caráter híbrido semiótico do texto científico e das mudanças nas possibilidades comunicativas da sociedade globalizada e que acabam por ter impacto na educação. Com este trabalho pretendemos contribuir para o corrente debate através da documentação, classificação e análise das interações discursivas em eventos de comunicação multimodal em uma sala de aula de Ciências, com respeito a dois aspectos principais: (i) o contexto de utilização dos diferentes modos semióticos relacionados com as atividades desenvolvidas em uma lição; (ii) as relações estabelecidas entre diferentes modos semióticos através da análise de um episódio selecionado. Nossos resultados mostram que ações, gestos e linguagem verbal modos foram mobilizados em contextos específicos, valorizados pelos interlocutores e tornados legítimos para efeito da comunicação pretendida naquela situação social. Os resultados destacam ainda a sensibilidade da professora na orquestração retórica do processo de construção de explicações coletivas pelos estudantes.

Palavras-chave: multimodalidade; sala de aula de ciências; educação em ciências; comunicação multimodal; gestos; linguagem

\begin{abstract}
There has been a growing awareness about the need to pay attention to the role of different semiotic modes, other than language, in the discursive construction of knowledge in the science classroom. Our research was conducted through extended videorecorded observations of secondary school Biology lessons and aimed at contributing to the current debate by analysing the multimodal character of discursive interactions in science classrooms with respect to two main aspects: (i) the context of use of different semiotic modes with respect to classroom activity in the context of four lessons (macroanalyses) and; (ii) the relationships between different semiotic modes through the analysis of one selected episode (microanalyses). Our results reveal that actions, gesture and verbal language were used in specific contexts, valued and legitimised by participants in the discursive interactions. The analysis also shows the teacher's ability in the rhetorical orchestration of the process through which students construct explanations.
\end{abstract}

Key-words: multimodality; science classroom; science education; multimodal communication; gesture; language 


\section{Introdução e quadro teórico de referência}

Questionar a centralidade atribuída à linguagem como recurso para a construção de significações nas salas de aula de Ciências, se faz necessário e urgente no atual contexto de mudanças nas possibilidades comunicativas da sociedade globalizada, que por sua vez geram impactos sobre programas curriculares e materiais didáticos. Pesquisas recentes no campo da Educação em Ciências têm sugerido a necessidade de dispensarmos maior atenção ao papel desempenhado por diferentes modos semióticos, e não somente pela a linguagem verbal, na construção discursiva do conhecimento científico em sala de aula (KRESS, OGBORN e MARTINS, 1998; LEMKE, 1998 e 2001; KRESS, JEWITT, OGBORN e TSATSARELIS, 2001; JEWITT, 2000 e 2001; MARQUEZ, 2000 e 2001). Pioneiros na construção de um quadro teórico de referência que articula idéias e procedimentos analíticos dos campos da Educação em Ciências e da Semiótica social Kress et al. (1998) abriram caminho para uma análise sistemática do papel das imagens e dos gestos na realização de funções retóricas (MARTINS et al 2001) e na construção de entidades científicas no discurso escolar (MARTINS 2000).

O ponto de partida destes diferentes estudos (JEWITT et al., 2001 e 2000; KRESS et al., 1998, 2000 e 2001; LEMKE, 2001; MÀRQUEZ et al., 2001) é a premissa de que os signos são negociados a partir das interações sociais, mediados por interesses pessoais e coletivos, envolvendo os diversos modos de comunicação disponíveis. Não nos comunicamos exclusivamente por meio da fala, mas sim pela sua articulação com imagens, gestos corporais, expressões faciais, movimentos de aproximação e de afastamento, os tons de voz, nosso jeito de vestir e de andar, entre tantos outros.

Fortemente influenciada por abordagens da Semiótica Social (HODGE e KRESS, 1988), esta visão caracteriza a comunicação como multimodal e enfatiza a estreita dependência entre modos de comunicação e características e demandas das situações sociais nas quais estes se inscrevem. Três aspectos principais merecem destaque. Em primeiro lugar, modos de comunicação são o resultado da organização de meios de comunicação "em sistemas de significação de forma a articular sentidos característicos das exigências sociais de diferentes comunidades” (KRESS et alli., 2001: 43). Para estes autores, os modos constroem sentidos de forma própria e os sentidos construídos nem sempre são compreendidos da mesma forma por diferentes grupos de leitores. Além disso, "os sentidos construídos pela linguagem, escrita ou falada, ... se entrelaçam com os sentidos construídos por todos os outros modos simultaneamente presentes e operantes num dado contexto comunicativo, sendo que esta interação também produz sentidos" (idem). Ou seja, sentidos são fruto da interação entre os modos. Finalmente os autores nos chamam atenção para o fato de que "o que pode ser considerado um modo comunicativo é quase sempre algo aberto -sistemas de significação são fluidos, modos de comunicação se desenvolvem e mudam em resposta às necessidades comunicativas da sociedade: novos modos são criados e modos existentes são transformados” (ibidem).

Kress et alli baseiam-se na idéia de Halliday (1985) de que, nas interações verbais com outros sujeitos, "temos $a$ nossa disposição redes de opções (ou conjuntos de alternativas semióticas) que são realizadas por meio de conjuntos de opções do sistema semântico" (KRESS et alli, 2001: 44). Essa perspectiva é ampliada por estes autores que incluem, como alternativas semióticas, a comunicação visual, os gestos e a ação. Estes modos se desenvolvem, a exemplo da linguagem verbal, por meio do uso social de forma a se constituirem em redes de recursos para a construção de signos que não são de modo algum arbitrários, mas carregados de interesses e marcado por traços que revelam decisões tomadas por seus produtores sobre qual significante se mostrou mais apto e plausível para a expressão do sentido desejado num dado contexto (idem).

Nessa perspectiva, grupos sociais distintos possuirão práticas semióticas diferentes. Por exemplo, como fruto da produção científica, encontramos uma variedade semiótica que envolve gráficos, funções e fórmulas matemáticas, descrição de atividades experimentais, entre outras. Na sala de aula o professor descreve organismos, apresenta em vídeo os ciclos da 
natureza, reproduz com as mãos os movimentos dos planetas, utilizando modos os quais não serão facilmente reconhecidos fora de seu contexto, de sua comunidade de pares. Dessa forma, a comunicação é analisada como evento multimodal e com referência a um contexto definido da atividade social. Aprender sobre a comunicação é, em parte, aprender a reconhecer os modos utilizados por essas comunidades.

Os trabalhos de Kress e colaboradores, (KRESS et al., 2000 e 2001; JEWITT et al., 2000 e 2001) apresentam uma singular abordagem para o ensino de Ciências, onde as relações e negociações sociais, mediadas pelos interesses dos participantes, influem diretamente na transformação e na aquisição de novos conhecimentos. A articulação entre conhecimento científico e cotidiano é fruto dessas negociações entre professores e alunos, com ampla interferência do contexto social adjacente (o grupo social ao qual pertencem os participantes, a mídia, o livro-didático, as aulas de outras disciplinas etc.).

Como esses autores, entendemos que a produção e circulação de signos, no universo escolar, são negociadas a partir de interações sociais (multimodais), mediadas por interesses pessoais e coletivos; pelos recursos semióticos disponíveis e orquestradas retoricamente. Partindo desse referencial teórico, procuramos, em nossa pesquisa contribuir para o corrente debate através da análise das interações discursivas de natureza multimodal em uma sala de aula de Ciências. Nosso trabalho pretende, portanto, investigar dois aspectos principais: (i) o contexto de utilização de diferentes modos semióticos relacionados com as atividades desenvolvidas em uma aula de ciências; (ii) as relações estabelecidas entre diferentes modos semióticos por meio da análise de um episódio selecionado.

\section{Métodos, participantes e contexto educacional}

Nosso estudo empírico envolveu extensas observações das aulas de Ciências durante o período de dois meses consecutivos em uma escola pública da rede municipal do Rio de Janeiro no ano de 2002. A turma observada possuía 36 estudantes, com idade entre 12 e 14 anos, cursando a $6^{\text {a }}$ série do Ensino Fundamental. O livro didático utilizado era Ciências -

$6^{\text {a }}$ série, de M. C. Santana, A. M. S. P Coelho e M. Waldhelm ${ }^{1}$. A professora, graduada em Biologia, tinha, à época, 15 anos de experiência profissional e habitualmente freqüentava cursos de formação continuada e participava de projetos de estudo e pesquisa na universidade. A coleta de dados incluiu a documentação em áudio e vídeo das aulas observadas, além da coleta de cópias do livro-didático utilizado e de fotocópias dos materiais produzidos pelos alunos durante as aulas. Esse material foi complementado com notas de campo feitas pela pesquisadora e por informações coletadas através de conversas informais com os estudantes e a professora. As transcrições foram feitas na íntegra e num formato que incluiu espaço para registro das formas de comunicação não verbal.

Com o objetivo de discutirmos a natureza multimodal da comunicação em sala de aula, apresentaremos neste artigo apresentamos nossas análises de apenas uma das aulas observadas. Esta discussão será dividida em duas partes. Inicialmente fazemos uma descrição global da aula destacando as relações entre os diferentes modos semióticos mobilizados por professora e alunos e as diferentes etapas de atividades em aula. Em seguida identificamos um episódio de forma a discutir de maneira mais aprofundada o papel de cada um dos modos semióticos que constituem as interações discursivas observadas na construção do conceito de célula pelos estudantes.

1 SANTANA, M.C.; COELHO, A. M.S.P. e WALDHELM, M. Ciências - $\sigma^{a}$ série. Rio de Janeiro: Editora do Brasil, 1999. 


\section{Resultados}

\section{A macroanálise: relações entre o uso de diferentes modos semióticos e a atividade de sala de aula.}

Nossas análises das interações em sala de aula se iniciaram com a classificação funcional das diferentes etapas da aula identificando, em cada uma delas, padrões típicos de interação discursiva. As etapas observadas foram: introdução, revisão, apresentação de um novo tópico, desenvolvimento e fechamento. Dentro de cada uma delas, fomos capazes de distinguir entre atividades de gerenciamento e atividades conceituais. São exemplos de atividades de gerenciamento: fazer a chamada, solicitar que os alunos se posicionem e abram o livro, recolher o trabalho de casa, dividir os estudantes em grupos, disciplinar a turma, organizar materiais para a realização dos procedimentos experimentais e de observação microscópica, entre outros. Atividades de caráter conceitual dizem respeito à leitura de um texto, anotações no caderno, recordação de conceitos, discussão e troca de idéias sobre um tópico da matéria estudada, ou ainda, construção, compartilhada ou não, de explicações. Seguimos identificando dentro destes espaços discursivos, marcados pelas atividades de gerenciamento e conceituais, diferentes episódios. Estes eram caracterizados por referência a temas específicos e por dinâmicas discursivas distintas.

Os episódios classificados foram então analisados com relação à presença de diferentes modos semióticos. Para tanto, utilizamos um modelo analítico desenvolvido por Kress et al. (2001) que nos permitiu identificar a forma como cada modo é utilizado e quando toma parte no processo comunicativo e, desta forma, mostrar como episódios estão estruturados do ponto de vista composicional.

Dentre os modos semióticos considerados nessa perspectiva analítica estão (i) o modo verbal, incluindo a fala e os textos escritos (no quadro de giz, no caderno, do livro didático, de textos de divulgação etc.); (ii) o modo gestual/ação, representado por uma série de movimentos do corpo, as mímicas representativas de conceitos ou de emoções, a manipulação de materiais diversos nos experimentos e demonstrações, enfim, as diversas atividades desempenhadas pelos indivíduos, utilizando o corpo, em especial a face, as mãos e os braços; (iii) o modo visual, com imagens impressas, estáticas ou em movimento, representadas em seus mais variados tipos e suportes (quadro, vídeo, microscópio, transparências etc.).

A tabela 1 mostra a relação entre estas categorias funcionais, organiza cronologicamente as diferentes atividades documentadas durante a aula 1 e registra o uso dos diferentes modos na comunicação de conceitos científicos. 


\begin{tabular}{|c|c|c|c|c|}
\hline \multirow{2}{*}{$\begin{array}{l}\text { Classifica } \\
\text { ção funcional }\end{array}$} & \multirow{2}{*}{ Atividade } & \multicolumn{3}{|c|}{ Modos semióticos } \\
\hline & & Verbal & Visual & Gestual \\
\hline $\begin{array}{l}\text { Início das } \\
\text { atividades: } \\
\text { apresentação da } \\
\text { pesquisadora, } \\
\text { objetivos da aula. }\end{array}$ & $\begin{array}{l}\text { Gerenciame } \\
\text { nto: pedidos de silêncio, } \\
\text { pedidos para abrir o livro } \\
\text { didático. }\end{array}$ & 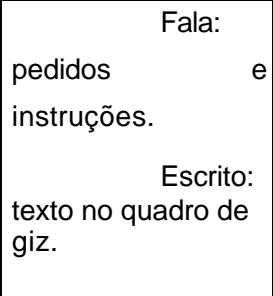 & $\begin{array}{l}\text { Objeto: } \\
\text { professora exibe a } \\
\text { página do livro } \\
\text { didático que será } \\
\text { trabalhada. }\end{array}$ & $\begin{array}{l}\text { Escrevendo } \\
\text { no quadro. } \\
\text { Circulando } \\
\text { pela sala de aula, se } \\
\text { aproximando e olhando a } \\
\text { atividade dos alunos. }\end{array}$ \\
\hline \multirow[t]{2}{*}{\begin{tabular}{|lr}
\multicolumn{1}{|c}{ Revisão } \\
de & conteúdos \\
discutidos em aulas \\
anteriores: o big- \\
bang, condições para \\
o surgimento da vida \\
na Terra (água e ar).
\end{tabular}} & $\begin{array}{l}\text { Conceitual: } \\
\text { professora lê trecho do } \\
\text { livro didático; faz a } \\
\text { revisão de tópicos do } \\
\text { conteúdo, através de } \\
\text { interações do tipo } \\
\text { perguntas e respostas. }\end{array}$ & 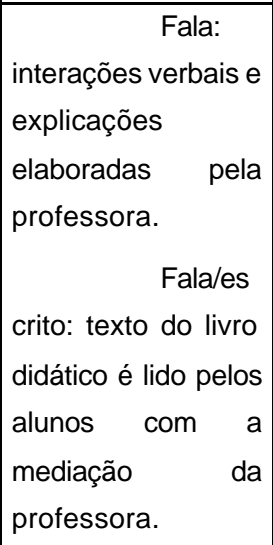 & $\begin{array}{l}\text { Imagem: } \\
\text { professora se refere a } \\
\text { representações do } \\
\text { livro para recordar o } \\
\text { relato sobre a criação } \\
\text { do universo. }\end{array}$ & $\begin{array}{l}\text { Professora } \\
\text { usa gestos para controlar } \\
\text { a participação dos alunos, } \\
\text { que significam conceitos } \\
\text { como gravidade e } \\
\text { atmosfera, através de } \\
\text { gestos e manipulações de } \\
\text { objetos concretos e } \\
\text { imaginários. }\end{array}$ \\
\hline & $\begin{array}{l}\text { Gerenciame } \\
\text { nto: professora pede } \\
\text { silêncio. }\end{array}$ & & & $\begin{array}{l}\text { Professora } \\
\text { para de falar e de andar e } \\
\text { repreende alunos que não } \\
\text { param de conversar. }\end{array}$ \\
\hline $\begin{array}{l}\text { Apresenta } \\
\text { ção de um assunto } \\
\text { novo: o primeiro ser } \\
\text { vivo foi um organismo } \\
\text { unicelular. }\end{array}$ & $\begin{array}{l}\text { Conceitual: } \\
\text { Professora conduz a } \\
\text { explicação e amplia a } \\
\text { participação dos alunos } \\
\text { com perguntas e } \\
\text { respostas. Leitura do } \\
\text { livro. }\end{array}$ & $\begin{array}{l}\text { Fala: } \\
\text { trocas verbais entre } \\
\text { professora e aluno. } \\
\text { Fala/es } \\
\text { crito: aluno lê texto } \\
\text { do livro. }\end{array}$ & $\begin{array}{l}\text { Estudante } \\
\mathrm{s} \text { fazem referência à } \\
\text { imagem do livro. }\end{array}$ & \begin{tabular}{|l}
\multicolumn{2}{c}{ Estudantes } \\
apontam imagem \\
manipulam o livro didático.
\end{tabular} \\
\hline Atividade & Gerenciame & Fala: & & Professora \\
\hline $\begin{array}{l}\text { s propostas para } \\
\text { alunos: } \\
\text { produção } \\
\text { individual de texto e } \\
\text { imagem, apresentação } \\
\text { para a classe. }\end{array}$ & $\begin{array}{l}\text { nto: professora dá } \\
\text { instruções e pede } \\
\text { organização dos alunos. } \\
\text { Faz a chamada. }\end{array}$ & $\begin{array}{l}\text { professora repete } \\
\text { instruções } \\
\text { específicas para a } \\
\text { execução da tarefa. } \\
\text { Pergunta o nome } \\
\text { dos alunos. }\end{array}$ & & $\begin{array}{l}\text { aponta para o trabalho } \\
\text { dos alunos. Eles } \\
\text { organizam materiais para } \\
\text { a realização do trabalho. } \\
\text { Professora caminha pela } \\
\text { sala de aula. }\end{array}$ \\
\hline
\end{tabular}




\begin{tabular}{|c|c|c|c|c|}
\hline para a classe. & 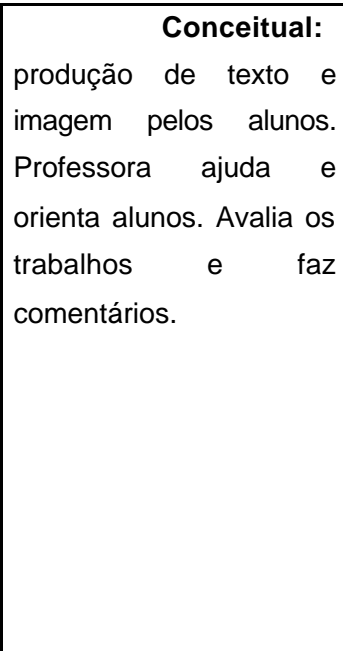 & 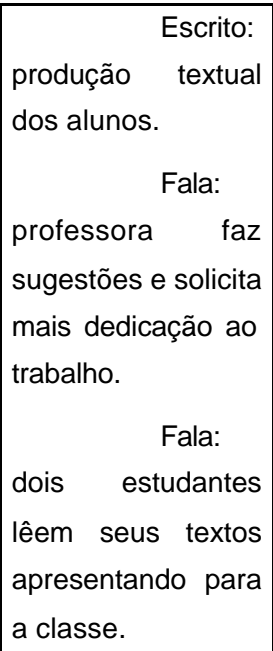 & $\begin{array}{l}\text { Estudante } \\
\text { s observam imagens } \\
\text { do livro. } \\
\text { Estudante } \\
\text { s desenham imagens } \\
\text { representativas da } \\
\text { formação do planeta } \\
\text { e do surgimento da } \\
\text { vida. }\end{array}$ & 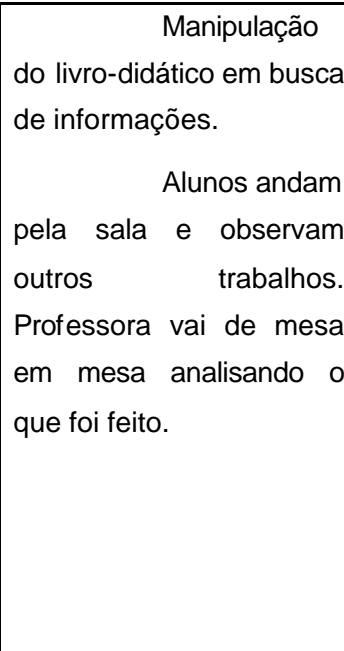 \\
\hline \begin{tabular}{l}
\multicolumn{2}{c}{ Fechamen } \\
to: indicação de \\
continuidade \\
discussão em aulas \\
posteriores.
\end{tabular} & $\begin{array}{l}\text { Gerenciame } \\
\text { nto: promessa de voltar à } \\
\text { discussão sobre o tema. }\end{array}$ & \begin{tabular}{|ll|}
\multicolumn{2}{|c|}{ Fala: } \\
antecipa & os \\
objetivos & da \\
próxima aula. & \\
\end{tabular} & & \\
\hline
\end{tabular}

Tabela 1: Síntese da macroanálise da aula 1.

A tabela nos permite verificar a enorme variedade de atividades realizadas pelos alunos e que visavam à construção de significações. Foram estimuladas: atividades de leitura, silenciosa individual e em voz alta para os colegas; produção de textos, orais, escritos e imagéticos; discussões em pequenos grupos. A atuação da professora envolveu exposições, leitura, comentários e explicações sobre o texto do livro didático, dirigidas à turma como um todo e também a indivíduos e pequenos grupos. O encadeamento das etapas segue um planejamento didático que se estende por várias aulas e que estimula o estabelecimento de relações entre conteúdos, dá espaço para a discussão de idéias trazidas pelos alunos e que procura, por meio de troca de idéias, convergir para a construção de significados estáveis e compartilhados.

Esta primeira análise possibilitou a verificação de que as interações de ordem gerencial são mais freqüentemente, mas não exclusivamente, realizadas através do modo verbal. A linguagem foi o recurso semiótico regularmente usado pela professora e pelos alunos sendo dominante no gerenciamento desta sala de aula. Em alguns momentos, entretanto, o modo gestual/ação se faz presente somando-se a dimensão paralinguística à expressão oral, no sentido de darem ênfase ou destaque para as palavras. Também observamos um repertório de posturas corporais, gestos com as mãos e expressões faciais que não representaram dificuldade para a interpretação dos estudantes (por exemplo, a professora cruza os braços, olha seriamente para a turma e imediatamente a gritaria pára).

Já as atividades de natureza conceitual usualmente envolveram o uso dos múltiplos modos (verbal - oral e escrito, gestual e visual). Nelas, gestos e ações adquiriram um papel distinto na construção de significações. Enquanto nas atividades gerenciais gestos e ações tenderam a reforçar expressões verbais, nas interações conceituais estes constituíram possibilidades de expressão que por vezes não encontraram paralelo em outros modos. As imagens destacam-se como um elemento essencial nas dinâmicas de comunicação entre professora e alunos. O livro-didático foi constantemente manuseado pelos alunos, que viravam suas páginas ativamente à procura de informações nos textos e nas representações visuais, no intuito de responderem as questões lançadas pela professora. 


\section{Construindo significações com diferentes modos semióticos: a microanálise dos dados.}

A macroanálise que relacionou aspectos da utilização dos diferentes modos semióticos com as atividades desenvolvidas em sala de aula foi complementada pela discussão do papel desempenhado por cada um dos modos na construção de significações pelos participantes das interações, professora e alunos (as). Diante da grande quantidade de dados gerados pela pesquisa, optamos por selecionar um episódio, o que nos permitiu ilustrar nossas análises de como os modos, neste caso o verbal e o gestual, se relacionam.

O episódio selecionado ocorreu no início da primeira aula observada, durante a etapa de revisão de conteúdos discutidos am aulas anteriores. Ele começa quando a professora interrompe a sua leitura de uma passagem do livro didático, que descreve as condições para o surgimento da vida no planeta Terra e pergunta aos estudantes o que é atmosfera.

A análise deste episódio, transcrito a seguir, mostra que ambos os modos, verbal e gestual, foram usados para construir uma resposta à pergunta da professora sobre o conceito de atmosfera e sua relação com a formação das condições para o surgimento da vida no planeta Terra. O formato da transcrição foi organizado de modo a registrar a diversidade de interações comunicativas e a incluir descrições de posturas dos participantes e aspectos paralinguísticos. 


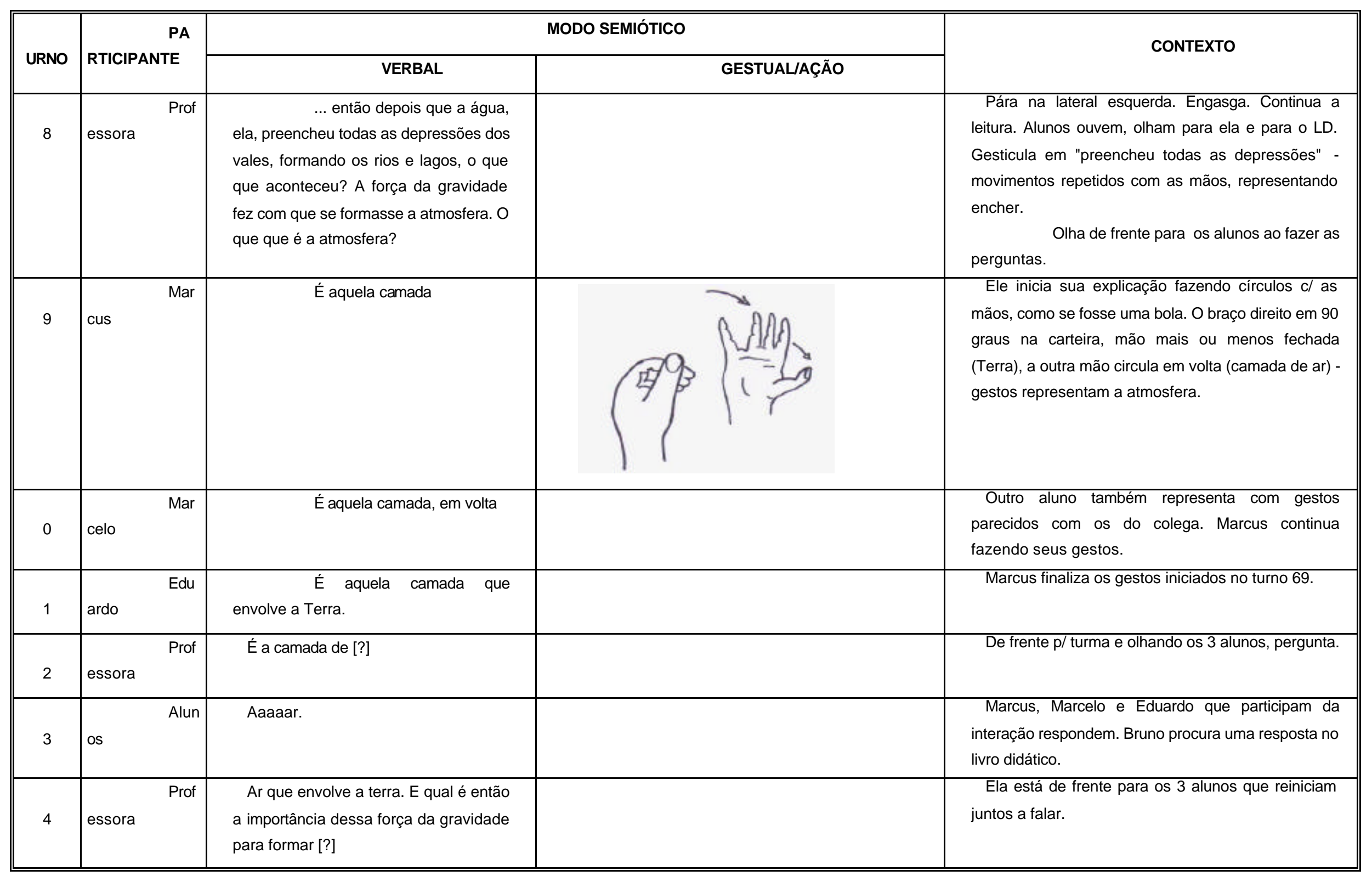




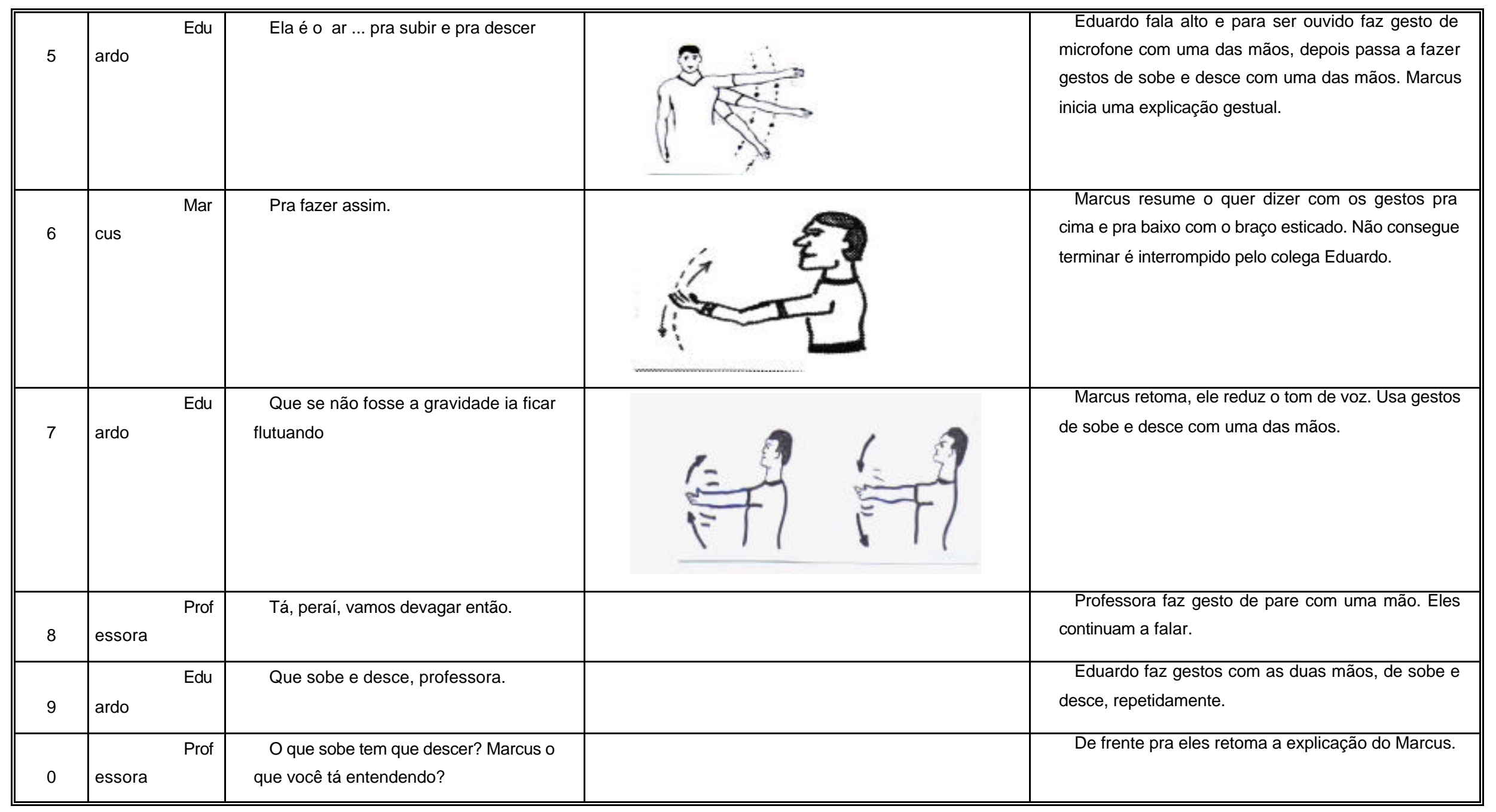




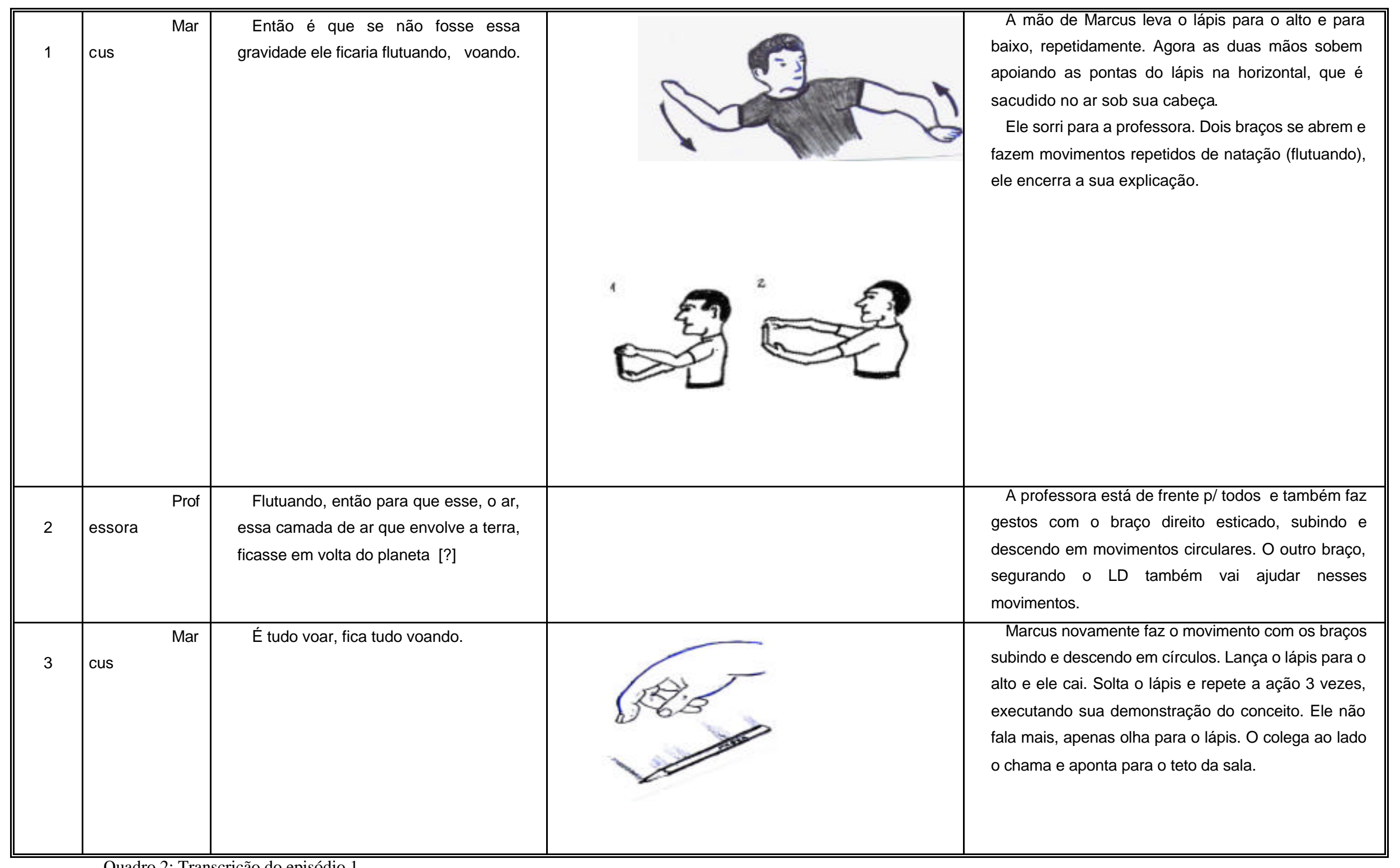

Quadro 2: Transcrição do episódio 1. 


\section{A cooperação entre os modos}

Vimos inicialmente que há uma grande solidariedade entre as palavras e os gestos. Isto pode ser visto, principalmente, nas interações dos turnos 68, 69 e 70. Nelas percebemos um paralelismo entre as enunciações verbais e os gestos que as acompanham, que serve ao propósito de expressar idéias. Este padrão discursivo foi característico tanto das enunciações da professora quanto das dos alunos. Os gestos ilustram a enunciação verbal que, por sua vez, especifica o sentido do gesto. Assim, explicaram-se reciprocamente, auxiliaram na elaboração de significados, expandindo sentidos e complementando-se mutuamente. É o caso da explicação elaborada por Marcus no turno 69. Na tentativa de responder a uma questão lançada pela professora ("O que que é atmosfera?"), sua resposta oral foi limitada, incompleta ("É aquela camad $\left.{ }^{\prime \prime}\right)$. Entretanto, sua mímica repetidas vezes encenada, complementou e ampliou sua resposta oral, em um exemplo clássico de cooperação entre os modos oral/gestual.

Em uma interessante atividade discursiva as entidades são primeiramente representadas por meio de gestos e somente depois nomeadas. Por exemplo: uma mão fechada representa a Terra, a outra mão aberta se movimenta circularmente em torno da mão fechada significando a ação "envolver". Mais tarde surgem as palavras ("Terra", "em volta", "envolve"). A construção discursiva das entidades que irão tomar parte na explicação (MARTINS et alli, 1999) é o primeiro passo para a formação de respostas às perguntas postas pela professora. Sentenças mais elaboradas e completas, e que se conformam a regras gramaticais, vão surgindo passo-a-passo, conjuntamente construídas pelos estudantes através da justaposição de palavras e gestos (turno 69 e 70), de forma a formarem sequências coerentes, as quais finalmente são enunciadas por um dos participantes nos turnos 71 e 73 e reforçada pela repetição da professora no turno 74 .

Quando um modo está subordinado a outro

Em algumas passagens percebemos o gesto e as ações subordinadas ao verbal. A opção pela linguagem como modo principal na construção de significações esteve ligada a três situações: para definir entidades que tomam parte nas explicações, se referir a seqüências de eventos e para enfatizar sentidos compartilhados pelos interlocutores. Por exemplo, no texto do livro didático, lido e comentado pela professora em turnos que antecedem imediatamente o episódio, o modo verbal se destacou na definição das entidades água (“um composto químico...”) e depressões (“cavidades de superfície sólida...”). Embora estas entidades estejam representadas no livro também por figuras, estas não apresentam as informações contidas no texto verbal (por exemplo, sobre composição molecular da água). A linguagem também se mostrou bastante apta em passagens que se referiam a processos que desenrolam no tempo, organizando-os cronologicamente, por meio do uso de advérbios, conjunções e construções que reforçam o caráter de temporalidade dos eventos (trechos sublinhados abaixo).

Sim, mas olha só vamos ver então, aí na página 15. Vamos nos localizar. "Depois surgiu a água $\mathrm{H}_{2} \mathrm{O}$, né? Estão vendo o segundo retângulo? [ ] Olha aqui Edson, olha lá, "A água é um composto formado por dois tipos de elementos químicos: o hidrogênio e o oxigênio. Como a temperatura da superfície da terra era provavelmente mais alta que o ponto de ebulição da água, essa substância só poderia estar em seu estado gasoso na atmosfera." Foi o que nós vimos agora. "A medida que a terra perdia calor e resfriava, o vapor condensou-se e encheu todas as depressões", é é "cavidades da superfície sólida da crosta do planeta, surgiram os mares e os oceanos". (professora, turno 66) ${ }^{2}$

No turno 69, vemos que a construção da pergunta evoca o texto lido e é realizada verbalmente. O gesto da professora é localizado e meramente enfatiza a idéia de preencher. Vimos, também, o modo gestual assumir também um papel complementar ao modo verbal nos turnos 75, 77 e 79, ao analisar a fala e os gestos de Eduardo. Ele expressa suas idéias (subir e descer, flutuar) sem problemas por meio de palavras cujos sentidos são compartilhados pelo grupo e os gestos conferem apenas um caráter de ênfase e reforço às palavras.

\footnotetext{
2 [ ] pausa curta

itálico texto escrito no livro didático
} 
Mas houve ocasiões nas quais o modo gestual foi a principal escolha do estudante. No turno 76, Marcus abre mão das palavras ao utilizar somente gestos para expressar a mesma idéia proposta por Eduardo (no turno 75). Os gestos também parecem ser mais eloqüentes no turno 81 quanto, frente a uma pergunta da professora, Marcus repete as mesmas palavras (flutuando, voando), mas propõe novos gestos e ações para expressar seus sentidos. São estes gestos que qualificam e explicitam o que Marcus quer dizer e que passam a ser o principal modo de comunicação e construção de sentidos. Neste caso, os gestos e as ações vão além das enunciações verbais, isto é, acrescentam informações novas. Eles representam um conhecimento acumulado, mas difícil de ser detalhado oralmente. Assim, extrapolam a intenção de ênfase do "já dito" e ajudam o aluno a construir significados mais complexos e a pensar sobre os conceitos em destaque (atmosfera e gravidade).

\section{As demandas da situação comunicativa}

A análise deste episódio nos permite perceber como os diferentes modos semióticos se organizam e se reformulam de modo a atender às demandas da situação comunicativa em questão. Ao mesmo tempo, novas possibilidades de articulação ajudam a moldar um novo ambiente para a sala de aula onde novas formas de comunicação se tornam próprias e legítimas. Tradicionalmente a linguagem verbal é valorizada como modo principal da construção de sentidos, mesmo em aulas de Ciências onde a linguagem matemática possui um status especial. No entanto neste episódio vimos situações nas quais o fato das palavras, ou os conceitos na forma verbal, não estarem disponíveis para os alunos não impediu a comunicação (por exemplo, nos turnos 75 e 76). Neste, e em outros casos, a variedade de expressões gestuais, ações de manipulação de objetos imaginários (o microfone no turno 75) e reais (o lápis no turno 81) foram cruciais para que os alunos pudessem pensar, tomar a palavra, expressar idéias e se comunicar com os colegas e com a professora, mantendo o fluxo discursivo e criando oportunidades para novas explicações. A professora aceitou e referendou o caráter multimodal das intervenções dos alunos quando ela própria incorporou gestos à sua enunciação discursiva (por exemplo, no turno 82) ou, de sua posição de autoridade, tornou-os uma forma válida de expressão (turnos 78 e 80). Assim o uso de diferentes modos não só caracteriza como ajuda a redesenhar o espaço da sala de aula como um cenário onde os sentidos são construídos a partir de escolhas por recursos semióticos que trazem a marca das intenções, expectativas e neces sidades dos participantes.

\section{Síntese e discussão}

Em nosso trabalho argumentamos que a análise das interações discursivas em uma perspectiva multimodal permite-nos entender melhor a complexidade da construção de sentidos na sala de aula de Ciências (Piccinini, 2003; Piccinini e Martins, 2003).

A macroanálise das aulas permitiu documentar uma variedade de usos dos diferentes modos em diferentes contextos pedagógicos. Atividades conceituais foram caracterizadas pela alternância na variedade de modos semióticos. Nas atividades de gerenciamento foram predominantes os modos verbal e gestual/ação, raramente observamos a presença do modo visual.

A aptidão dos diferentes modos se manifestou, mais especificamente, em contextos distintos da explicação. Por exemplo, o modo verbal mostrou-se mais apto em situações que se referiam a cronologia de eventos. No entanto, na reconstrução da explicação por parte do estudante o modo gestual e as ações foram mediadores essenciais para a construção do texto verbal. Neste episódio a linguagem gestual foi essencial para que o aluno, carente de um maior repertório verbal para consolidar uma explicação, pudesse significar e explicar os conceitos envolvidos na resposta à pergunta da professora. Foi por meio de gestos que o aluno foi capaz de se comunicar com a professora, seja através das demonstrações (lápis caindo), seja através de mímicas (braços nadando no ar ou mãos balançando o lápis) que experimentaram formas de representar os conceitos. Nesse caso o modo gestual se mostrou mais apto para realizar a expressão dos conceitos em discussão, atmosfera e gravidade, por parte dos alunos. O uso de braços e mão - que sobem, descem e giram no espaço, e o lançamento do lápis no 
ar compõem movimentos explicativos elaborados pelos alunos, baseados no que eles sabem sobre a atmosfera e a força da gravidade. Os gestos têm o papel de representar as situações imaginadas pelos interlocutores, que em parceria no jogo de perguntas e respostas da professora, construíram a narrativa sobre as condições para o surgimento da vida no planeta Terra. Assim, os resultados deste estudo destacaram contextos nos quais o uso de diferentes modos semióticos permitiu um fluxo homogêneo de comunicação e auxiliaram elaborações conceituais por parte dos estudantes. Nesse caso, as imagens e o texto do livro-didático ficam apagados em relação a outros modos e, até mesmo o modo oral se vê subordinado ao modo gestual, no caso da explicação dos alunos (Piccinini, 2003).

Em resumo, verificamos neste episódio que a fala e os gestos desempenharam papéis específicos nas interações entre professora e aluno. Estes papéis foram reconhecidos pelos participantes, especialmente pela professora, que não ficou restrita à expressão verbal de uma definição conceitual como forma única de resposta às questões propostas. Em outras palavras, os modos foram mobilizados em contextos específicos, valorizados pelos interlocutores e tornados legítimos para efeito da comunicação pretendida naquela situação social. O processo de construção de sentidos em questão se inscreveu dentro de uma prática educativa que valoriza as contribuições dos estudantes, considera sua produção textual como etapa essencial na construção de sentidos e respeita o ritmo e o caráter tentativo das explicações produzidas pelos estudantes Esta abertura, traduzida em interações que se caracterizam pela justaposição ou pela a articulação dos diferentes modos semióticos na construção de um texto multimodal, viabilizou a comunicação entre os participantes e se constituiu nos primeiros passos da construção compartilhada de sentidos para as entidades em questão ${ }^{3}$. Estes aspectos, destacados pela análise, são reveladores de orientações mais amplas que subjazem à organização desta sala de aula como um espaço de construção e revelam uma profes sora comprometida com o estímulo à participação dos estudantes e a conseqüente valorização das suas idéias no processo de construção de conhecimentos. Assim, além do percurso dos estudantes, a microanálise dos dados contribui para revelar aspectos essenciais da tarefa diária desta professora de explicar ciências em sala de aula, em especial de sua habilidade para orquestrar retoricamente o processo de construção de uma explicação coletiva pelos estudantes e que, por normalmente passarem desapercebidos, acabam por não se constituir em objeto de reflexão e análise pelo professor.

\section{Agradecimentos}

As autoras agradecem o apoio do Conselho Nacional de Desenvolvimento Científico e Tecnológico (CNPq), da Fundação Carlos Chagas de Amparo à Pesquisa do Estado do Rio de Janeiro (FAPERJ) e da Secretaria Municipal de Educação do Rio de Janeiro (SME/RJ). Um agradecimento especial à professora que nos permitiu realizar esta pesquisa em sua sala de aula e aos alunos participantes.

\section{Referências}

GOUVÊA, G. E MARTINS, I. Imagens e educação em ciências. In: ALVES, N. e SGARBI, P. Espaço e imagens na escola. Rio de Janeiro: DP\&A, 2001.

JEWITT, C. et al. Teaching and learning: beyond language. Teaching Education, Vol 7, nº 3, p. 327-341, 2000.

JEWITT, C. et al. Exploring learning through visual, actional and linguistic communication: the multimodal environment of a science classroom. Education Review, Vol 53, nº1, p. 5-18, 2001.

KRESS, G. e van LEEUWEN, T. Reading images: the grammar of visual design. London, Routledge, 1996.

3 As interações prosseguiram no sentido de esclarecer, em momentos posteriores, confusões conceituais, recorrentes neste nível de ensino e contexto de discussão, entre atmosfera e gravidade. 
KRESS, G; OGBORN, J.; MARTINS, I.. A sattelite view of language: some lessons from science classrooms Language Awareness, Vol 7, nº 2 \& 3, p. 69- 89, 1998.

KRESS, G.; JEWITT, C.; OGBORN, J. e TSATSARELIS, C. Multimodal teaching and learning: the rhetorics of the science classroom. London: Continuum, 2001.

LEMKE, J. L. Multiplying meaning: visual and verbal semiotics in scientific text. In: MARTIN, J. R. e VEEL R. (Eds.) Reading Science: functional perspectives on discourses of science. London, Routledge, 1998.

MARTINS I Rhetorics of science communication. In: Proceedings of the VI Interamerican Conference on Physics Education, Canela, RS, Brasil, 2000.

LEMKE, J.L. Teaching all the languages of science: words, symbols, images and actions. Brooklyn College, City University of New York. Disponível em: http://academic.brooklyn.cuny.ed/education/jlemke/. Acesso em 13 de mar. 2001.

MÀRQUEZ, C et al. Interactions in the classroom. Dialogue: multimodal communication. In: Anais Third International Conference of European Science Education Research Association, 2001, Thessaloniki: Greece, Vol1, p. 125-127.

MARTINS, I et al. Uma análise das imagens nos livros didáticos de Ciências para o ensino Fundamental. In: Anais do IV Encontro Nacional de Pesquisa em Educação em Ciências, Bauru: São Paulo, CD-rom, 2004.

MORTIMER, E. e MACHADO, A. H. A Linguagem numa aula de ciências. In: Presença Pedagógica. Vol.2, n 11, p. 49$57,1996$.

PICCININI, C.L. Análise da comunicação multimodal na sala de aula de Ciências: um estudo envolvendo o conceito de célula. Dissertação de Mestrado. Núcleo de Tecnologia Educacional para a Saúde, Universidade Federal do Rio de Janeiro, 2003.

PICCININI, C. L. e MARTINS, I. Observando o trabalho com imagens na sala de aula de Ciências. In: Anais do II Encontro Regional de Ensino de Biologia, 2003, UFF: Niterói, p. 179 - 182.

DATA DE RECEBIMENTO: $11 / 10 / 04$

DATA DE APROVAÇÃO:25/01/05 